\title{
Advances in the management of adult obstructive sleep apnea
} Jeremy A Weingarten and Robert C Basner*

\author{
Address: Division of Pulmonary, Allergy and Critical Care Medicine, Columbia University Cardiopulmonary Sleep and Ventilatory Disorders \\ Center, New York, NY 10032, USA \\ *Corresponding author: Robert C Basner (rcb42@columbia.edu) \\ FI000 Medicine Reports 2009, I:48 (doi:10.3410/MI-48)
}

The electronic version of this article is the complete one and can be found at: http://FI000.com/Reports/Medicine/content/l/48

\begin{abstract}
Obstructive sleep apnea (OSA) is associated with cognitive impairment, daytime sleepiness, and cardiovascular and cerebrovascular morbidity and mortality. Continuous positive airway pressure (CPAP) remains the primary treatment for this disorder, and recent data provide novel insight regarding optimal CPAP application and compliance. Promising alternate forms of OSA treatment have also been addressed with recent clinical research.
\end{abstract}

\section{Introduction and context}

Obstructive sleep apnea (OSA), a prevalent disorder in adults defined by repetitive upper-airway obstruction and asphyxia, is associated with fatal and non-fatal cardiovascular and cerebrovascular adverse effects [1-3]. Continuous positive airway pressure (CPAP) remains the first-line treatment for this disorder, with randomized controlled trials repeatedly demonstrating efficacy of CPAP in improving OSA symptoms [4,5]. A preponderance of current clinical research focuses on optimizing application of, and compliance with, CPAP, which appears to be essential for the successful treatment of OSA-related morbidity and mortality [1].

\section{Recent advances}

\section{CPAP and quality-adjusted life years}

A 2009 review of randomized controlled trials up to November 2006 analyzed incremental costs per qualityadjusted life years and found that CPAP was more costeffective than oral appliances or conservative treatment alone in the treatment of OSA [6].

\section{Pressure variable and auto-titrating devices}

Positive airway pressure (PAP) devices may be modified to lower late inspiratory and/or early expiratory fixed positive pressure in an attempt to minimize discomfort and improve adherence with CPAP. Although standard bilevel PAP therapy has not been shown to improve compliance compared with CPAP [7], bilevel PAP with flexible expiratory pressure was recently associated with better compliance than a CPAP control group in OSA patients previously poorly compliant with CPAP [8]. In contrast, a randomized controlled trial of expiratory pressure-relief CPAP versus fixed-pressure CPAP in a group of patients with moderate OSA found no betweengroup difference regarding apnea hypopnea index (AHI), subjective sleepiness, side effects, or compliance at 7 weeks [9].

Auto-titrating CPAP, programmed with device-specific algorithms such that airway pressure varies with the requirements of the upper airway, has also been studied in regard to compliance in numerous recent randomized trials; these generally have shown compliance similar to that of auto-titrating and fixed-pressure devices [10-13], although one study did find that compliance was significantly higher in the auto-titrating CPAP group (up to 0.5-0.7 more hours per night than fixed CPAP) [14]. Other sleep parameters, including AHI, were essentially equivalent for fixed and auto-titrating CPAP among these studies. Two recent randomized trials investigated the efficacy of auto-adjusting CPAP applied to OSA patients exclusively in the ambulatory setting. CPAP compliance and improvement in subjective daytime sleepiness were similar in a group randomly assigned to ambulatory diagnostic and auto-titrating 
CPAP compared with a group receiving sleep laboratory polysomnographic diagnosis and CPAP titration at 6-week follow-up [15]. A 3-month trial in patients with a high probability of OSA demonstrated a similar AHI in patients treated with auto-titrating CPAP alone and patients who underwent polysomnographic diagnosis and CPAP titration [16]. Sleep apnea-related quality of life and subjective sleepiness were similarly improved in the two groups, while CPAP compliance was higher in the autotitrated CPAP group.

\section{Adaptive servo-ventilation}

A recent randomized crossover trial [17] demonstrated that adaptive servo-ventilation (ASV), a form of bilevel PAP which self-adjusts to a patient's breathing pattern, was significantly more effective than titrated bilevel PAP with a back-up rate in decreasing the $\mathrm{AHI}$ in patients with central and mixed sleep apneas, including 'complex' sleep apnea (an entity in which central apneas become evident in OSA patients during CPAP application). A review of 100 consecutive patients treated with ASV for central sleep apnea, Cheyne-Stokes breathing, and/or complex sleep apnea after unsuccessful CPAP titration, similarly demonstrated overall superiority of ASV in improving AHI compared with bilevel PAP with and without a back-up rate, and compared with CPAP [18].

\section{Other modalities for improving CPAP compliance}

In the initial phase of the flexible bilevel PAP study noted above [8], interventions including mask fitting, heated humidification, pharmacologic nasal patency therapy as indicated, and systematic education improved CPAP compliance by $24 \%$, confirming that a significant portion of non-compliance with CPAP can be modulated with these measures $[19,20]$, as recommended in the current practice parameters of the American Academy of Sleep Medicine [21].

\section{Other treatment modalities \\ Weight loss}

While improvement of OSA has been demonstrated in morbidly obese individuals with weight loss following bariatric surgery $[22,23]$, recent work indicates that complete resolution of OSA is rarely achieved with gastric banding despite significant weight loss [24]. More recent data extend these findings to patients with lesser degrees of obesity undergoing non-surgical weight loss: in a population of obese patients (body mass index 28-40) with mild OSA (AHI 5-15), a very low calorie diet for 12 weeks along with supervised dietary and exercise counseling throughout a 1-year study period resulted in significantly greater improvement in weight loss and sleep-disordered breathing parameters (including AHI and percentage time with oxygen saturation below 90\%) compared with a control group with minimal weight loss intervention [25]. Cure rates for OSA (AHI <5) at 12 months were $63 \%$ in the intervention group and 35\% in the control group.

\section{Positional therapy}

A recent randomized crossover trial using a thoracic antisupine band that nearly abolished sleep in the supine position demonstrated significant improvement in AHI in most patients with mild to moderate supinepredominant OSA [26]. However, this improvement was significantly less than the improvement in AHI achieved with CPAP in these patients.

\section{Oral appliances}

A recent randomized trial demonstrated that, in patients with mild to moderate OSA, a mandibular advancement device and CPAP each resulted in significant improvement in sleep-disordered breathing, sleep apnea-related quality of life, and morning diastolic blood pressure; CPAP was more effective than the oral appliance in decreasing sleep-disordered breathing and subjective daytime sleepiness [27]. These data are consistent with a recent meta-analysis that found that, although oral appliances and CPAP similarly improve OSA symptoms, oral appliances are generally inferior to CPAP in improving objective sleep-disordered breathing parameters [28]. In the most recent update of the American Academy of Sleep Medicine practice parameters, oral appliances are suggested for patients with mild to moderate OSA who do not respond to CPAP or who prefer an oral appliance [29].

\section{Cardiac resynchronization therapy}

Two recent studies investigated the efficacy of cardiac resynchronization therapy, with associated improvement in hemodynamic function, in ameliorating OSA diagnosed in patients with heart failure. One study showed no significant effect [30]; the other [31] found a significant decrease in the AHI, which, however, remained in the range of moderate to severe (mean AHI 29.5). In a recent randomized trial [32], atrial overdrive pacing set at a rate of 15 beats higher than the average nocturnal rate mildly improved AHI in this setting but was inferior to the effect of CPAP.

\section{Implications for clinical practice}

Current data continue to support CPAP as primary therapy for the treatment of OSA, particularly in patients with severe OSA and those at high risk for cardiovascular morbidity. Recent research confirms the efficacy of interventions such as systematic education and mask fitting in improving CPAP compliance. Consistent with a previous meta-analysis that considered trials up to 2004 
[7], recent data do not definitively support the superiority of auto-titrating or pressure-relief CPAP to fixedpressure CPAP in regard to patient compliance or other OSA variables. However, the use of such technology regarding longer-term clinical outcomes remains to be defined, and the applications of auto-titrating CPAP exclusively in the outpatient setting in patients with a high likelihood of OSA and of pressure-relief PAP in patients poorly compliant with CPAP are particularly promising. Weight loss should continue to be a major treatment consideration in all overweight patients with OSA. Oral appliances continue to represent a reasonable alternative to CPAP, particularly in milder forms of the disorder. Further studies of PAP regimens for OSA in patients with heart failure and complex sleep apnea, including ASV, are likely to better define the role of such therapy in improving OSA outcomes in these settings.

\section{Abbreviations}

AHI, apnea hypopnea index; ASV, adaptive servoventilation; $\mathrm{CPAP}$, continuous positive airway pressure; OSA, obstructive sleep apnea; PAP, positive airway pressure.

\section{Competing interests}

RCB has been funded with an unrestricted grant from the ResMed Foundation to study adaptive servo-ventilation outcomes in patients with acute heart failure and Cheyne-Stokes breathing. JAW declares that he has no competing interests.

\section{References}

I. Campos-Rodriguez F, Peña-Griñan N, Reyes-Nuñez N, De la CruzMoron I, Perez-Ronchel J, De la Vega-Gallardo F, Fernandez-Palacin A: Mortality in obstructive sleep apnea-hypopnea patients treated with positive airway pressure. Chest 2005, I 28:624-33.

2. Marin JM, Carrizo SJ, Vicente E, Agusti AG: Long-term cardiovascular outcomes in men with obstructive sleep apnoeahypopnoea with or without treatment with continuous positive airway pressure: an observational study. Lancet 2005, 365: 1046-53.

3. Peppard PE, Young T, Palta M, Skatrud J: Prospective study of the association between sleep-disordered breathing and hypertension. N Engl J Med 2000, 342:1378-84.

4. Giles TL, Lasserson TJ, Smith BH, White J, Wright J, Cates CJ: Continuous positive airways pressure for obstructive sleep apnoea in adults. Cochrane Database Syst Rev 2006, 3:CD00I I06.

5. Basner RC: Continuous positive airway pressure for obstructive sleep apnea. N EnglJ Med 2007, 356:175I-8.

6. McDaid C, Griffin S, Weatherly H, Durée K, van der Burgt M, van Hout S, Akers J, Davies RJ, Sculpher M, Westwood M: Continuous positive airway pressure for the treatment of obstructive sleep apnoea-hypopnoea syndrome: a systematic review and economic analysis. Health Technol Assess 2009, 13:I-274.

7. Haniffa M, Lasserson TJ, Smith I: Interventions to improve compliance with continuous positive airway pressure for obstructive sleep apnoea. Cochrane Database Syst Rev 2004, CD003531.

8. Ballard RD, Gay PC, Strollo PJ: Interventions to improve compliance in sleep apnea patients previously non-compliant with continuous positive airway pressure. J Clin Sleep Med 2007. 3:706-12.

9. Nilius G, Happel A, Domanski U, Ruhle KH: Pressure-relief continuous positive airway pressure vs constant continuous positive airway pressure: a comparison of efficacy and compliance. Chest 2006, 130:1018-24.

I0. Fietze I, Glos M, Moebus I, Witt C, Penzel T, Baumann G: Automatic pressure titration with APAP is as effective as manual titration with CPAP in patients with obstructive sleep apnea. Respiration 2007, 74:279-86.

II. Mulgrew AT, Cheema R, Fleetham J, Ryan CF, Ayas NT: Efficacy and patient satisfaction with autoadjusting CPAP with variable expiratory pressure vs standard CPAP: a two-night randomized crossover trial. Sleep Breath 2007, I I:3 I-7.

12. Nolan GM, Doherty LS, Mc Nicholas WT: Auto-adjusting versus fixed positive pressure therapy in mild to moderate obstructive sleep apnoea. Sleep 2007, 30:189-94.

13. Nussbaumer Y, Bloch KE, Genser T, Thurnheer R: Equivalence of autoadjusted and constant continuous positive airway pressure in home treatment of sleep apnea. Chest 2006, I 29:638-43.

14. To KW, Chan WC, Choo KL, Lam WK, Wong KK, Hui DS: A randomized cross-over study of auto-continuous positive airway pressure versus fixed-continuous positive airway pressure in patients with obstructive sleep apnoea. Respirology 2008, 13:79-86.

15. Berry RB, Hill G, Thompson L, McLaurin V: Portable monitoring and autotitration versus polysomnography for the diagnosis and treatment of sleep apnea. Sleep 2008, 31:1423-31.

FI000 Factor 3.0 Recommended

Evaluated by James A Rowley 24 Feb 2009

16. Mulgrew AT, Fox N, Ayas NT, Ryan CF: Diagnosis and initial management of obstructive sleep apnea without polysomnography: a randomized validation study. Ann Intern Med 2007, 146:157-66.

FI000 Factor 3.0 Recommended Evaluated by James A Rowley II Apr 2007

17. Morgenthaler TI, Gay PC, Gordon N, Brown LK: Adaptive servoventilation versus noninvasive positive pressure ventilation for central, mixed, and complex sleep apnea syndromes. Sleep 2007, 30:468-75.

18. Allam JS, Olson EJ, Gay PC, Morgenthaler TI: Efficacy of adaptive servoventilation in treatment of complex and central sleep apnea syndromes. Chest 2007, 132:1839-46.

19. Hoy CJ, Vennelle M, Kingshott RN, Engleman HM, Douglas NJ: Can intensive support improve continuous positive airway pressure use in patients with the sleep apnea/hypopnea syndrome? Am J Respir Crit Care Med 1999, 159:1096-100.

20. Massie CA, Hart RW, Peralez K, Richards GN: Effects of humidification on nasal symptoms and compliance in sleep apnea patients using continuous positive airway pressure. Chest 1999, I 16:403-8.

21. Kushida CA, Littner MR, Hirshkowitz M, Morgenthaler TI, Alessi CA, Bailey D, Boehlecke B, Brown TM, Coleman J Jr, Friedman L, Kapen S, Kapur VK, Kramer M, Lee-Chiong T, Owens J, Pancer JP, Swick TJ, Wise MS: Practice parameters for the use of continuous and bilevel positive airway pressure devices to treat adult patients with sleep-related breathing disorders. Sleep 2006, 29:375-80.

22. Buchwald $H$, Avidor $Y$, Braunwald $E$, Jensen $M D$, Pories $W$, Fahrbach K, Schoelles K: Bariatric surgery: a systematic review and meta-analysis. JAMA 2004, 292:I724-37.

23. Dixon JB, Schachter LM, O'Brien PE: Polysomnography before and after weight loss in obese patients with severe sleep apnea. Int J Obes (Lond) 2005, 29:1048-54.

24. Lettieri CJ, Eliasson AH, Greenburg DL: Persistence of obstructive sleep apnea after surgical weight loss.J Clin Sleep Med 2008, 4:333-8.

25. Tuomilehto HP, Seppa JM, Partinen MM, Peltonen M, Gylling H, Tuomilehto JO, Vanninen EJ, Kokkarinen J, Sahlman JK, Martikainen T, 
Soini El, Randell J, Tukiainen H, Uusitupa M: Lifestyle intervention with weight reduction: first-line treatment in mild obstructive sleep apnea. Am J Respir Crit Care Med 2009, 179:320-7.

26. Skinner MA, Kingshott RN, Filsell S, Taylor DR: Efficacy of the 'tennis ball technique' versus nCPAP in the management of position-dependent obstructive sleep apnoea syndrome. Respirology 2008, I3:708-I5.

27. Lam B, Sam K, Mok WY, Cheung MT, Fong DY, Lam JC, Lam DC, Yam LY, Ip MS: Randomised study of three non-surgical treatments in mild to moderate obstructive sleep apnoea. Thorax 2007, 62:354-9.

28. Lim J, Lasserson TJ, Fleetham J, Wright J: Oral appliances for obstructive sleep apnoea. Cochrane Database Syst Rev 2006, CD004435.

29. Kushida CA, Morgenthaler TI, Littner MR, Alessi CA, Bailey D, Coleman J Jr, Friedman L, Hirshkowitz M, Kapen S, Kramer M, Lee-
Chiong T, Owens J, Pancer JP; American Academy of Sleep: Practice parameters for the treatment of snoring and Obstructive Sleep Apnea with oral appliances: an update for 2005. Sleep 2006, 29:240-3.

30. Oldenburg O, Faber L, Vogt J, Dorszewski A, Szabados F, Horstkotte D, Lamp B: Influence of cardiac resynchronisation therapy on different types of sleep disordered breathing. Eur J Heart Failure 2007, 9:820-6.

31. Stanchina ML, Ellison K, Malhotra A, Anderson M, Kirk M, Benser ME, Tosi C, Carlisle C, Millman RP, Buxton A: The impact of cardiac resynchronization therapy on obstructive sleep apnea in heart failure patients: a pilot study. Chest 2007, 132:433-9.

32. Sharafkhaneh A, Sharafkhaneh H, Bredikus A, Guilleminault C, Bozkurt $B$, Hirshkowitz M: Effect of atrial overdrive pacing on obstructive sleep apnea in patients with systolic heart failure. Sleep Med 2007, 8:3I-6. 